\title{
Effects of Prescribed Fire on Understory Vegetation in a Canarian Pine Forest Stand (Canary Islands, Spain)
}

\author{
José Ramón ARÉVALO ${ }^{1}$, Silvia FERNÁNDEZ-LUGOㄹ, Virginia AFONSO ${ }^{1}$, Federico GRILLO², Agustín \\ NARANJO ${ }^{3}$
}

${ }^{1}$ Departamento de Biología Vegetal (Área de Ecología), Facultad de Biología, Universidad de La Laguna, 38206 La Laguna, Spain.

${ }^{2}$ Seguridad y Control de Riesgos, Estructura de Teleformación, Universidad de Las Palmas de Gran Canaria, 35003 Las Palmas de Gran Canaria, Spain.

${ }^{3}$ Departamento de Geografía, Facultad de Geografía e Historia, Universidad de Las Palmas de Gran

Canaria, 35003 Las Palmas de Gran Canaria, Spain.

* corresponding author: jarevalo@ull.edu.es.

Bulletin USAMV series Agriculture 71(2)/2014

Print ISSN 1843-5246; Electronic ISSN 1843-5386

DOI 10.15835/buasvmcn-agr: 10849

\begin{abstract}
Historically, fire has played a dominant role in shaping many forest plant communities. Mediterranean-type vegetation is one of the world's major fire-prone biomes, with conifer forests among the most flammable ecosystems in the Mediterranean region. Prescribed fires are a powerful tool for reducing fire hazards by decreasing amounts of fuel. The main objective of this work is to analyse the effects of prescribed burning on the understory vegetation composition and species richness in a reforested stand of Pinus canariensis. Nine $900 \mathrm{~m}^{2}$ plots were settled in areas were prescribed burning had been applied in the last 5 years; their respective control plots were established in nearby unburnt areas of similar environmental conditions. In each plot, we systematically selected 10 points in which we sampled the presence of species in $1 \mathrm{~m}^{2}$ quadrats and analysed for species richness and species composition. No significant changes in the number of species richness were found medium term after prescribed burning. Also, when we analysed species composition, no discrimination among the control and burnt plots was detected. From an ecological point of view, prescribed fire is a good practice to reduce biomass accumulation in $P$. canariensis reforested stands, resulting in low effects in species composition and richness. However, it would be necessary long-term studies to evaluate the effects of prescribed burning intensity, season and frequency, as well as positive effects on the naturalization of these artificial stands.
\end{abstract}

Keywords: fire, fuel-load management, pine forest, reforestation, vegetation dynamics.

\section{INTRODUCTION}

Until the 1960s, fire was seen as a disaster to be prevented if possible (Kornas, 1958; Molinier, 1968). However, since Leopold et al. (1963) reported the negative aspects of fire suppression in ecosystems, fire has being seen as an endogenous factor of communities, which occurrence may be a result of community structure and composition (White, 1979).

Nowadays, fire is considered a natural force in most plant communities and should be allowed to play a greater role where possible (Wright and Bailey, 1982; Perry, 1994). In Mediterranean ecosystems, fire is considered an important influence on the vegetation structure (Naveh, 1975; Trabaud, 1994).

Fires are recurrent in the Canarian pine forest, although their occurrence in the same area more than once within a 20-year period is rare (del Arco et al., 1992). A 15-year study of fire impact in the Canary Islands revealed that this impact is not durable or pernicious for the natural ecological process (Höllerman, 2000).

Management of pine forest in Mediterranean countries usually involves cutting the shrub understory to break fuel continuity within the canopy (Pérez and Moreno, 1998) before prescribe fire. Burning without cutting was not possible 
due to the danger of canopy torching under the present fuel model. Cutting reduces understory cover and the abundance of vertical fuel ladders. However, due to debris in the field after the cutting treatment, fuel loads remain high and light availability to the soil surface is reduced, which can also affect species composition.

The objective of this study was to analyse the effects of clearing and prescribed fire treatments on the understory plant community by testing the following main hypotheses: 1) prescribe burning has significant effects in species richness and diversity; 2) prescribe burning has significant effect in species composition.

Appropriate tools of analysis should reveal important aspects about species dynamics with respect to prescribe burning that will help in the management of reforested stands.

\section{METHODS}

The study was conducted at the pine forest of Artenara, Gáldar, Moya and Valleseco, in Gran Canaria, Canary Islands, Spain, which are part of the Protected Landscape of Las Cumbres, under environmental protection by the Canarian Network of Natural Protected Areas (Gobierno de Canarias, 1994).

The plots of the study are located between 1400-1600 $\mathrm{m}$ a.s.l. Mean annual temperature, humidity and rainfall (for 2006-2008) are $17.7^{\circ} \mathrm{C}$, $52.2 \%$ and $500 \mathrm{~mm}$ respectively. The dominant tree species is Pinus canariensis, although the area includes some planted exotic pine species such as $P$. halepensis and $P$. radiata. The understory vegetation is dominated by a variety of shrub and herb species, where the most representative species are Chamaecytisus proliferus, Teline microphylla and Micromeria benthami.

Nine plots of $30 \times 30 \mathrm{~m}$ where located in areas were prescribe burning was implemented in the last 5 years. From several weeks to a month before burning, the woody understory vegetation of all plots and the lowest branches of the pines were cleared, with the help of chain-saws, except in the controls, as in usual practice to break the vertical continuous fuel ladder before burning. Dead fuel was kept on the ground.

This practice allows a homogeneous burning, and maintains flame heights of less than $1.5 \mathrm{~m}$ (Grillo et al., 2009).
Burning was carried out under specific temperature $\left(18-26^{\circ} \mathrm{C}\right)$, humidity $(30-70 \%)$ and wind $(<15 \mathrm{~km} / \mathrm{h})$ conditions.

Strip fires, a burn method that consist in setting successive parallel strips of fire, and back fires, in which the line of fire is set on the downwind side of the fuel and the fire moves slowly against the wind, were used to achieve ignition.

Near the burned plots, control plots in an unburned area with the same environmental condition were located and sampled in the same way as the burned ones.

In each plot, ten $1 \mathrm{~m}^{2}$ subplots were located systematically (for burned and control plots), and all the species in the subplots were listed. Also, environmental variables such as rock, soil and litter cover percentage were visually estimated per subplot. Altitude, aspect and slope were also measured per subplot.

We have compared species richness and Wilson \& Smith evenness index (Magurran, 2004) with a parametric paired t-test (for a $\mathrm{p}<0.05, \mathrm{n}=9$ for species richness and $\mathrm{n}=7$ for evenness; evenness base in frequency of species in the ten plots) for burned and control plots. Normality of the data was checked with the Kolmogorov-Smirnov test, and homocedasticity of the data was examined with a Levene contrast (for $\mathrm{p}<0.05$ ).

Ordination techniques help to explain community variation (Gauch, 1982), because they are useful tools to evaluate trends through time, as well as space (ter Braak and Šmilauer, 1998).

We used Detrended Correspondence Analysis (DCA; Hill and Gauch, 1980) on CANOCO 4.5 (ter Braak and Šmilauer, 1998) to examine how the species composition changed between burned and control plots. Analyses were based on frequency (of the ten plots). Basic statistical methods followed Zar (1984) and were implemented using the SPSS statistical package (SPSS, 1986).

\section{RESULTS AND DISCUSSION}

We found a total of 29 species (Appendix I). Of these species, some of them appeared associated only to prescribe burned plots as Argyranthemum adauctum, Ferlula linkii or Pteridium aquilinum, while others only appeared in control plots, but 
only Asphodelus ramosus in an important number. However, when we compared species richness, the analysis did no revealed significant differences $(\mathrm{t}=$ $0.44, \mathrm{n}=9$; control $=4.07 \pm 1.04 \mathrm{SD}$; burnt $=4.20$ \pm 1.48 SD). When the Wilson \& Smith evenness index was compared between control and burned plots (only for seven pair of plots as long as two plots of the remaining pairs had only one species), it revealed not significant differences $(\mathrm{t}=0.86, \mathrm{n}=9$; control $=0.13 \pm 0.05 \mathrm{SD}$; burnt $=0.15 \pm 0.06 \mathrm{SD}$ ).

Many studies suggest an overall trend of increasing species richness and diversity with prescribed fire (Knapp et al., 2007; Rego et al., 1991) and a rapid recovery after a low- to moderate-intensity fire (Arévalo et al., 2014).

The increase in richness has been detected to take place during the first to second year after fire and it is more remarkable in annual and herbaceous species (Rego et al., 1991), being related to canopy opening and higher light availability at soil surface after fire (Arévalo and Fernández-Palacios, 2008).

In this study, the lack of differences in species richness or evenness between the groups of plots is related with the time recovery of the plots that obviously is faster as long as prescribed burning is of low-medium intensity as explained in methods.

Species composition analyses for the plots, revealed a lack of differences between species composition of both, control and prescribe burned plots. Again, the explanation can be related with the time gap (aprox. 5 years) since the burning that allowed the recovery of the species composition in the burned plots.

Not even through DCA-axis I or axis II it is possible to infer any difference (Figure 1), and the species composition variation should be related with aspect of environmental characteristics or plots history.

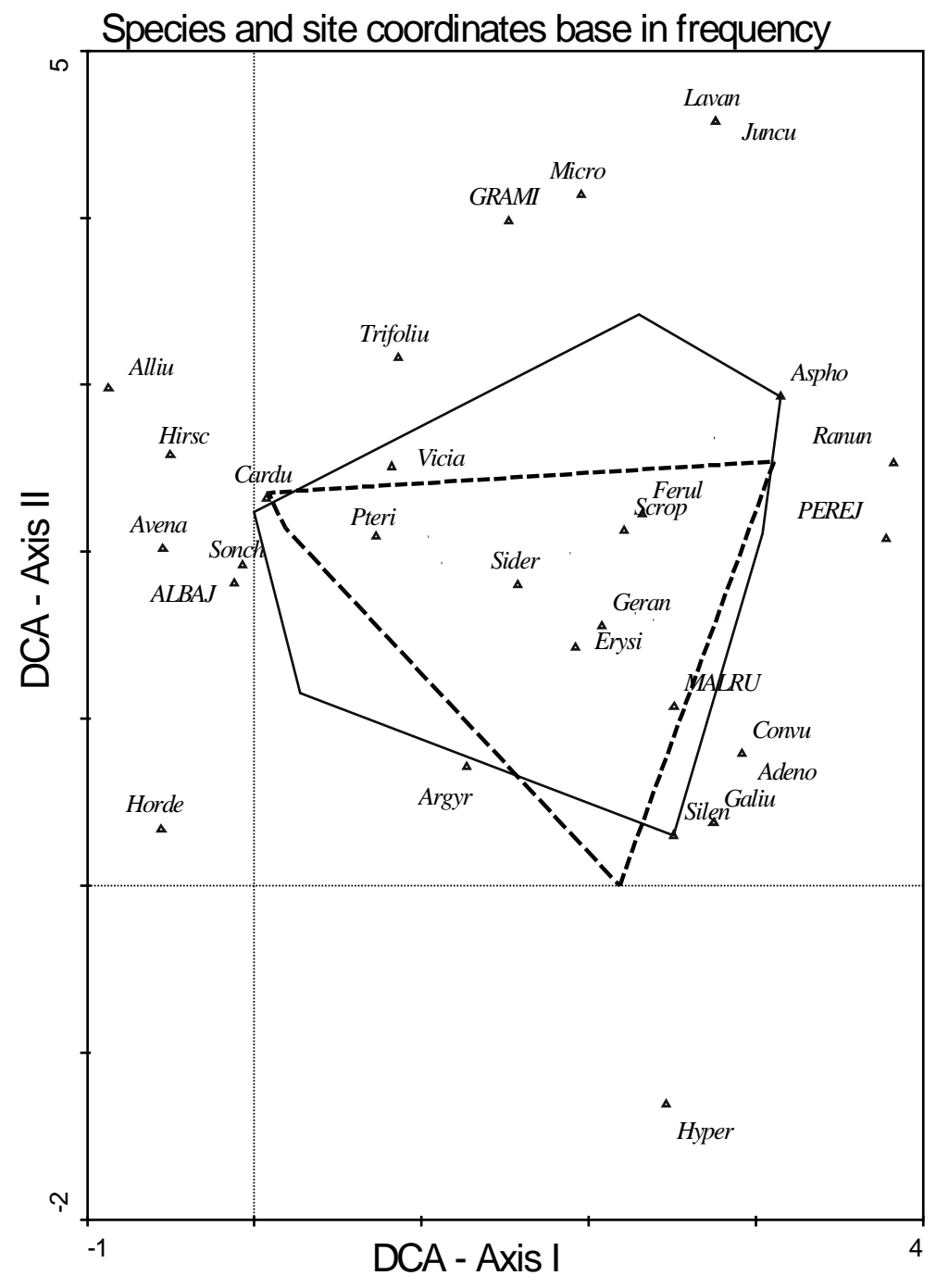

Fig. 1. Detrended Correspondence Analysis (DCA) ordination diagram showing species and samples according to treatment. Plot coordinates of prescribe burned vs. control plots are enclosed in an envelope (dashed black line and black line respectively). Eigenvalues for the first and second axes were 0.62 and 0.33 , respectively. Cumulative percentage variance of species data for both axes was 31\%. The species appeared with the five first letters of the genus or the common name (in case of not identification). 
Restoration programs of the Canarian pine forest have been very common since 1930, existing 15,103 ha of Canarian pine plantations, which require management practices to reach a more natural stage (Arévalo and Fernández-Palacios, 2005). In this framework, prescribed burning can operate not only as a management tool for fire prevention, but also as a tool for achieving restoration objectives (Messier et al., 2013).

With these results and from an ecological point of view, prescribed fire can be consider as an useful and low cost management practice to reduce biomass (Xanthopoulos et al., 2006; Fernandez and Botelho, 2003) without negative effects in plant composition as well as a tool for increasing recreational values and restoring fire prone ecosystems (Hesseln et al., 2004; Brown et al., 2004).

Appendix I. Plant species (29 spp.) recorded during the research. In bold are indicated the species found only in burned plots. $\left({ }^{*}\right) \mathrm{ni}=$ non identified.

\begin{tabular}{lll}
\hline Adenocarpus foliolosus & Galium sp. & Geranium 2 (ni) \\
Albajaca $($ ni) & Geranium 1 (ni) & Pteridium aquilinum \\
Allium sp. & Gramin (ni) & Ranunculus cortusifolius \\
Argyranthemum adauctum & Hirschfeldia incana & Scrophularia sp. \\
Asphodelus ramosus & Hordeum sp. & Sideritis dasygnaphala \\
Avena sp. & Hypericum grandifolium & Silene vulgaris \\
Carduus sp. & Juncus sp. & Sonchus sp. \\
Convulvulus sp. & Lavandula sp. & Trifolium sp. \\
Erysimum bicolor & Malrubio (ni) & Vicia sp. \\
Ferlula linkii & Micromeria sp. & \\
\hline
\end{tabular}

\section{REFERENCES}

1. Arévalo, J.R. and Fernández-Palacios, J.M. (2008). Natural regeneration of Pinus canariensis Chr. Sm. Ex DC in Buch in forest plantations after thinning. The Open Forest Science Journal 1: 54-60.

2. Arévalo, J.R. and J.M. Fernández-Palacios, J.M. (2005). From pine plantations to natural stands. Ecological restoration of a Pinus canariensis Sweet, ex Spreng forest. Plant Ecology 181: 217-226.

3. Arévalo, J.R., Fernández-Lugo, S., Naranjo-Cigala, A., Salas, M., Ruíz, R. Ramos, R. and Moreno, M. (2014) Post-fire recovery of an endemic Canarian pine forest. International Journal of Wildland Fire 23: 403-409.

4. Brown, R.T., Agee, J. K. and Franklin, J.R. (2004). Forest restoration and fire: Principles in the context of place. Conservation Biology 18: 903-912.

5. Del Arco, M.J., Pérez, P.L., Rodríguez, O., Salas, M. and Wildpret, W. (1992). Atlas Cartográfico de los Pinares Canarios II: Tenerife. Viceconsejería de Medio Ambiente y Conservación de la Naturaleza (Consejería de Política Territorial, Gobierno de Canarias).

6. Fernandes, P.M. and H.S. Botelho. (2003). A review of prescribed burning effectiveness in fire hazard reduction. International Journal of Wildland Fire 12: 117-128.

7. Gauch, H.G. Jr. (1982). Multivariate Analysis in Community Ecology . Cambridge University Press, Cambridge.

8. Gobierno de Canarias (1994). Ley 12/1994, de 19 de diciembre, de Espacios Naturales de Canarias. Boletín Oficial de Canarias, 24 de Diciembre de 1994, Nº157.
9. Grillo Delgado, F., Díaz Fababú, D. and Camaño Azcárate, J. (2009). III Curso Europeo Avanzado de Manejo de Fuego, Las Palmas de Gran Canaria.

10. Hesseln, H., Loomis, J.B. and González-Cabán, A. (2004). Comparing the economic effects of fire on hiking demand in Montana and Colorado. Journal of Forest Economics 10: 21-35.

11. Hill, M.O. and Gauch, H.J. Jr. (1980) Detrended Correspondence Analysis: an improved ordination technique. Vegetatio 42: 47-58.

12. Höllermann, P. (2000). The impact of fire in Canarian ecosystems 1983-1998. Erdkunde 54: 70-75.

13. Knapp, E.E. and Schwilk, D.W., Kane, J.M. and Keeley, J.E. (2007). Role of burning season on initial understory vegetation response to prescribed fire in a mixed conifer forest. Canadian Journal of Forest Research 37: 11-22.

14. Kornas, K. (1958). Succession regressive de la vegetation des garrigues sur les calcarires compacts dans la Montagne de la Gardiole, pres de Montpellier. Acta Societatis Botanicorum Poloniae 27: 563-596.

15. Leopold, A.J., Cain, S.A., Cottam, C.M., Gabrielson, I.N. and Kimball, T.L. (1963). Wildfire management in the national parks. Am. For. 69: 32-35/61-63.

16. Magurran, A.E. (2004). Measuring Biological Divertity. $1^{\mathrm{a}}$ Ed. Oxford, United Kingdom. Blackwell Science Ltd.

17. Messier, C., Puettmann, K.J. and Coates, K.D. (2013). Managing Forests as Complex Adaptive Systems: Building Resilience to the Challenge of Global Change. Earthscan from Routledge. 
18. Molinier, R. (1968). La dynamique de la vegetation provençale. Collection Botanique Et appliquees 60: 119-208.

19. Naveh, Z. (1975). The evolutionary significance of fire in the Mediterranean regio. Vegetatio 29: 199-208.

20. Pérez, B. and Moreno, J.M. (1998) Fire-type and forest management effects on the early vegetation dynamics of a Pinus pinaster woodland. Plant Ecology 134: 27-41.

21. Pérez, B. and Moreno, J.M. (1998). Fire-type and forest management effects on the early vegetation dynamics of a Pinus pinaster woodland. Plant Ecology 134: 27-41.

22. Perry, D.A. (1994). Forest ecosystems. Baltimore: The John Hopkins University Press.

23. Rego, F.C., Bunting, S.C. and Silva, J.M. (1991). Changes in understory vegetation following prescribed fire in maritime pine forest. Forest Ecology and Management 41: 21-31.

24. SPSS (1986) SPSS/PC+ V.6.0. Base manual. SPSS Inc., Chicago, IL.
25. ter Braak, C.J.F. and Šmilauer, P. (1998). CANOCO Reference Manual and User's Guide to Canoco for Windows: Software for Canonical Community Ordination (version 4). Microcomputer Power. Ithaca, NY.

26. Trabaud, L. (1994). Postfire plant community dynamics in the Mediterranean basin. In: The role of fire in Mediterranean ecosystems. Eds. J.M. Moreno, W.C. Oechel: 1-15. SpringerVerlag, New York.

27. White, P.S. (1979). Pattern, process, and natural disturbance in vegetation. Bot. Rev. 45: 229-299.

28. Wright, H.A. and Bailey, A.W. (1982) Fire Ecology. New York: Wiley.

29. Xanthopoulos, G., Caballero, D., Galante, M., Alexandrian, D., Rigolot, E. and R. Marzano (2006). Forest Fuels Management in Europe. USDA Forest Service Proceedings: 29-46.

30. Zar, J.H. (1984). Biostatistical analysis. $2^{\text {nd }}$ ed. Prentice-Hall, Englewood Cliffs, NJ. 